8 Moehring MA, Spencer MP: Power M-mode Doppler (PMD) for observing cerebral blood flow and tracking emboli. Ultrasound Med Biol 2002;28:49-57.

9 Spencer MP, Moehring MA, Jesurum J, Gray WA, Olsen JV, Reisman $\mathrm{M}$ : Power m-mode transcranial Doppler for diagnosis of patent foramen ovale and assessing transcatheter closure. J Neuroimaging 2004; $14: 342-349$.

Dr. Vijay Sharma

Division of Neurology, Department of Medicine

National University Hospital

Singapore 119074 (Singapore)

Tel. +65 6772 2516, Fax +65 68723566

E-Maildrvijay@singnet.com.sg

\section{Cerebrovasc Dis 2007;24:481 \\ DOI: 10.1159/000108925 \\ Reply to the Letter by Sharma and Chan: Is Transcranial Doppler for the Detection of Venous-to-Arterial Circulation Shunts Reproducible?}

\section{S. Sastry, K. Daly, T. Chengodu, C.N. McCollum \\ Department of Academic Surgery, South Manchester University Hospital, Manchester, UK}

We agree with Sharma and Chan [1] that the recent study by Belvis et al. [2] is further evidence that transcranial Doppler (TCD) is a simple, reliable and minimally invasive approach to the diagnosis and quantification of venous-to-arterial circulation shunts (v-aCS).

Our study clearly demonstrated the importance of optimising and then standardising the preparation of microbubbles [3]. We also believe that standardising the provocation tests, particularly the Valsalva manoeuvre, is important in achieving reliable and reproducible results.

In addition to anatomical reasons why the number of bubbles traversing the heart may be higher in the sitting rather than supine position, our experience is that a more stable TCD signal can be maintained in the sitting position $[4,5]$.
We agree that power M-mode TCD may improve the detection and quantification of $\mathrm{v}$-aCS. It may be possible to adapt the criteria for $\mathrm{v}$-aCS used in our study if the number of microbubbles detected by power M-mode TCD can be compared with the number on standard TCD; if power M-mode detects 50\% more microbubbles, our definition of a 'significant' $\mathrm{v}$-aCS would be $\geq 20 \mathrm{mi}$ crobubbles. Whilst a study to compare power M-mode and standard TCD would be worthwhile, we are concerned with Sharma and Chan's suggestion of repetitive testing for $\mathrm{v}$-aCS. There have been 5 case reports of transient ischaemic attack and 1 of stroke following intravenous injection of agitated air and saline during echocardiography $[6,7]$. Our practice is to limit the number tests wherever possible and to stop testing once a large shunt has been demonstrated for safety reasons.

\section{References}

1 Sharma VK, Chan BPL: Comment on 'Is transcranial Doppler for the detection of veous-to-arterial circulation shunts reproducible?' Cerebrovasc Dis 2007;24:480-481.

2 Belvis R, Leta RG, Marti-Fabregas J, Cocho D, Carreras F, Pons-Llado G, et al: Almost perfect concordance between simultaneous transcranial Doppler and transesophageal echocardiography in the quantification of right-to-left shunts. J Neuroimaging 2006;16:133-138.

3 Sastry S, Daly K, Chengodu T, McCollum C: Is transcranial Doppler for the detection of venous-to-arterial circulation shunts reproducible? Cerebrovasc Dis 2007;23:424-429.

4 Sastry S, Riding G, Morris J, Taberner D, Cherry N, Heagerty A, McCollum CN: The role of venous-to-arterial circulation shunts and thrombophilia in myocardial infarction and ischaemic stroke in young adults. J Am Coll Cardiol 2006;48:686-691.

5 Purandare N, Oude Voshaar RC, Burns A, Velupandian UM, McCollum C: Paradoxical embolization: a potential cause of cerebral damage in Alzheimer's disease? Neurol Res 2006;28:679-684.

6 Dittrich HC: Transient ischemic attack after air-contrast echocardiography. Ann Intern Med 1995;123:731-732.

7 Srivastava TN, Undesser EK: Transient ischemic attack after air contrast echocardiography in patients with septal aneurysm. Ann Intern Med 1995;122:396.

Sanjay Sastry

Department of Academic Surgery

South Manchester University Hospital

Southmoor Road, Manchester M23 9PT (UK)

Tel. +44161291 5853, Fax +441612915854

E-Mail cnmcc@manchester.ac.uk 